\title{
Study on Phenolic Content in Fast Pyrolysis Oil Obtained from the Model Compounds of Three Major Components in Biomass
}

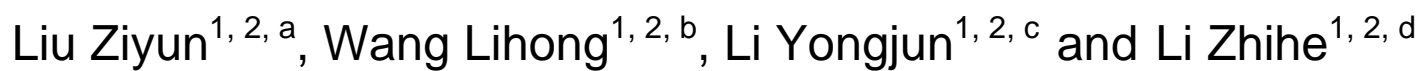 \\ ${ }^{1}$ School of Agricultural and Food Engineering, Shandong University of Technology, China, \\ ${ }^{2}$ Shandong Research Center of Engineering and Technology for Clean Energy, Zibo 255049, \\ Shandong Province, China; \\ a1071224997@qq.com bwanglh@sdut.edu.cn cliyongjun@sdut.edu.cn dizhihe@sdut.edu.cn
}

Keywords: cellulose; xylan; lignin; pyrolysis; phenolic compounds

Abstract. The aim of this paper is to research variation of phenolic yields in bio-oil and the effect of interactions of three components in biomass, fast pyrolysis experiments were done with cellulose, xylan (as an alternative to hemicellulose) and lignin in tube furnace at different temperatures. Phenolic yields in liquid product analyzed by using Gas chromatography-Mass spectrometry (GC-MS) were divided into four groups: phenols, H-phenols, G-phenols and S-phenols.

In single component oil, S-phenols yeild was hardly any. There were trends for phenols, $\mathrm{H}$-phenols and G-phenols that were consistent with temperature increasing from 450 to $550^{\circ} \mathrm{C}$. And in cellulose oil, $\mathrm{H}$-phenols was prone to dehydroxylation near $500^{\circ} \mathrm{C}$. The phenolic compounds yields in lignin oil reached $25.98 \%$ at $550^{\circ} \mathrm{C}$. For two-component oil, the yields of phenols and G-phenols increased due to the interaction of cellulose-lignin, while that of $\mathrm{H}$-phenols decreased. The interaction of xylan-lignin was similar with cellulose-lignin. The interaction of cellulose-xylan on phenolic yields was relatively weak. S-phenols generated in maize straw pyrolysis oil and the phenolic total yeild in the oil was higher than modular materials oil. Interaction among three components inhibited phenols yields and restrained G-phenols at $550^{\circ} \mathrm{C}$ remarkablely.

\section{Introduction}

With the pollution of environment and the exhausted use of the fossil fuel, bio-energy is considered as renewable energy and alternative fuel, which has aroused a great interest. Owning to its advantages of low- sulfur, low-nitrogen and carbon-neutral, biomass has become an increasing significant potential energy for utilizing [1]. Pyrolysis is considered to be an effective way to obtain bio-oil. Bio-oil contains hundreds of organics, such as acids, phenols, aldehydes and alcohols [2]. Phenols is regarded as a kind of high value-added chemical product, which can be used to synthesize phenolic resin adhesives, medicines, spices and so on [3].

Biomass materials are mainly composed of cellulose, hemicellulose, lignin, inorganic metal, organic extract and many more. Wherein, cellulose, hemicellulose and lignin account for about $80 \%$ of the dry weight of biomass, and they play an important role in the pyrolysis process of biomass [4, 5]. Also they are polymers with complex structure and thermal weight loss characteristics are easily affected by many factors $[6,7]$.

Recently a lot of studies have been made on the interaction among cellulose, hemicellulose and lignin. On one hand, some researchers believe that the three major components'(cellulose, hemicellulose and lignin) pyrolysis behavior to a large extent characterizes the pyrolysis behavior of biomass, so there is no interaction among the three components in the pyrolysis process $[8,9]$. But on the other hand, researchers found that the three components are not separated during pyrolysis reaction. Therefore, complicated interaction may exist in biomass pyrolysis process which can impact the products [10-12]. For example, Huang et al. [10] investigated the interaction between cellulose and lignin and he found that hemicellulose inhibits the pyrolysis activity of cellulose, because the concentration of cellulose pyrolysis products were increased with small molecule hydrocarbon compounds, as well as water content in the pyrolysis products of hemicellulose. Lignin inhibits the generation of laevoglucose in cellulose pyrolysis oil and promotes it cleave into small molecules at 
$800^{\circ} \mathrm{C}$. Meanwhile cellulose has a promoting effect on lignin pyrolysis, and the interaction between hemicellulose and cellulose is weak [11]. It has been reported that the calculated results of gaseous product were in disagreement with the experimental one, showing existing interaction among the components when biomass is in pyrolysis process in a fluidized bed [12].

Superposition calculation is often used to verify whether there is an interaction between the three components, Zhao et al. [6] found that the calculated values of the pyrolysis products of the components are in agreement with the experimental values of biomass pyrolysis. It can be concluded that it is feasible to use the superposition method to calculate the pyrolysis products in the range of 350 to $650^{\circ} \mathrm{C}$. Previous studies $[13,14]$ consider that the best experimental temperature is about $500{ }^{\circ} \mathrm{C}$ to produce the highest yield and the best quality of bio-oil for the majority of biomass and the three components. In order to investigate the interaction between cellulose, hemicellulose and lignin on the pyrolysis products (especially phenols) well, a study of the three major components pyrolysis has been carried out by using gas chromatography-mass spectrometry. 450,500 and $550^{\circ} \mathrm{C}$ were set as the experimental temperatures. Three component model compounds (individual component, two components and three components) were used as raw materials to carry out the pyrolysis in tube furnace.

\section{Experiment}

\subsection{Samples}

Cellulose (C), xylan (X) and lignin (Y) were used as raw samples to investigate the pyrolysis of biomass in the study. Based on the average initial fraction of maize straw [15], four proportions of $1: 1(\mathrm{C}: \mathrm{X}), 3: 1(\mathrm{C}: \mathrm{L}), 3: 1(\mathrm{X}: \mathrm{L})$ and $3: 3: 1(\mathrm{C}: \mathrm{X}: \mathrm{L})$ were used to study the interactions of these components. Microcrystalline cellulose powder were purchased from Aladdin Industrial Corporation; xylan powder, as hemicellulose modular replacement was obtained from beechwood were purchased from Sigma Corporation; while lignin powder, were gotten from Sigma Corporation. The particles sizes of the three samples (cellulose, xylan and lignin) are smaller than $100 \mu \mathrm{m}$.

\subsection{Pyrolysis process}

Fast pyrolysis of cellulose, xylan and lignin were conducted with a tubular reactor that is composed principally of electric heating controller, pyrolysis reaction tube (inside diameter: $55 \mathrm{~mm}$; total length: $680 \mathrm{~mm}$ ) and cooling and collecting products section (two stage condensations), as shown in Fig.1.

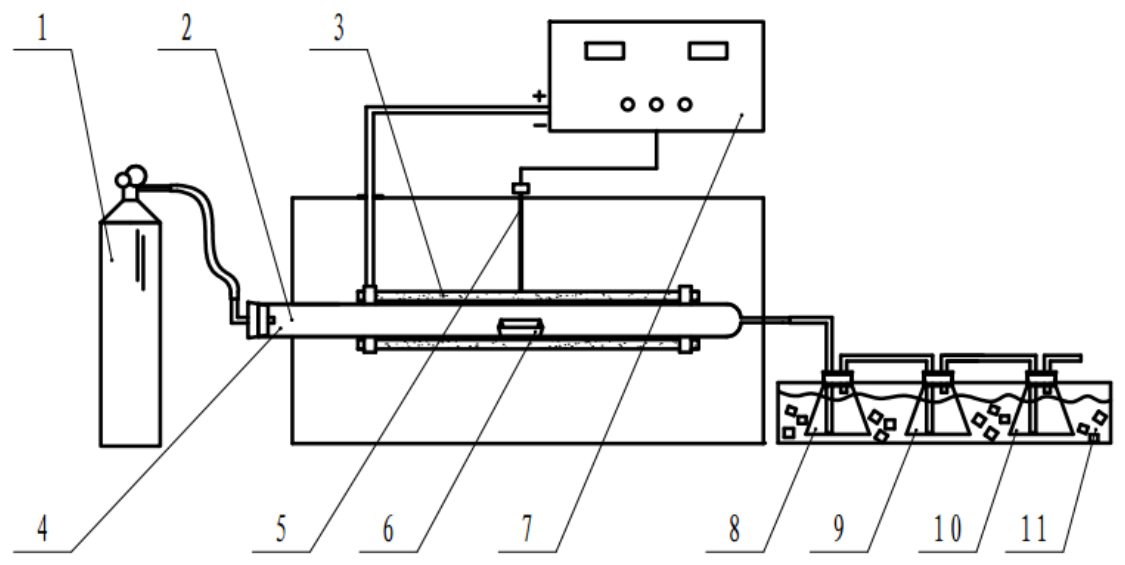

Nitrogen 2. Quartz tubular reactor 3. Electric heater 4. Feeder 5. Thermocouple
6. Porcelain boat 7. Temperature controller
8. 9. Oilpot
10.Desiccator 11. Cooling water

Fig.1 Fixed bed tube furnace

In each experiment, the pyrolysis temperature was set by the electric heater controller; meanwhile Nitrogen with a flow rate of $280 \mathrm{~mL} / \mathrm{min}$ was flushed into the TGA to maintain an inert atmosphere for thermal decomposition of the samples during the experiment. Until the temperature was steady, the porcelain boat (size: $50 \mathrm{~mm} \times 20 \mathrm{~mm} \times 10 \mathrm{~mm}$ ) with samples was rapidly pushed into the tuber 
reactor. The samples were quickly heated in the furnace and reached the furnace temperature in $1 \mathrm{~s}$. Subsequently, condensable gas was condensed and collected in the oilpot, and the non-condensable gas was collected in case of polluting the atmosphere. Make sure that the three experiments were conducted at the same condition. Then they were carried out.

\subsection{Bio-oil analysis by GC-MS}

Gas Chromatograph-Mass Spectrometer-computer was used to analyze the liquid product in this study. The GC /MS analysis was carried out by a HP-5890 gas chromatograph with split injection at $290^{\circ} \mathrm{C}$. The column used was a $60 \mathrm{~m} \times 0.25 \mathrm{~mm}$ i.d. with a $0.25 \mathrm{~mm}$ film thickness. The temperature program is as follows: Helium (99.999\% high purity) was used as the carrier gas with a flow rate of 1 $\mathrm{ml} / \mathrm{min}$. The GC oven temperature was set initially at $40^{\circ} \mathrm{C}$ for $1 \mathrm{~min}$, then that was programed to $240^{\circ} \mathrm{C}$ at a rate of $5^{\circ} \mathrm{C} / \mathrm{min}$. The oven temperature was held at $240^{\circ} \mathrm{C}$ for $5 \mathrm{~min}$. The inlets temperature was maintained at $250^{\circ} \mathrm{C}$. The transfer line was set at $280^{\circ} \mathrm{C}$ and the MS ion source was set at $250^{\circ} \mathrm{C}$ with $70 \mathrm{eV}$ electron energy. Data acquisition was performed by comparing the spectra of the components with the database of spectra of known components stored in the GC-MS library. The run time was 80 min totally.

\section{Results and discussion}

\subsection{Individual component's pyrolysis behavior}

Bio-oil contains a variety of phenolic compounds that can be divided into phenols, H-phenols (derived from hydroxyphenyl), G-phenols (derived from guaiacyl) and S-phenols (derived from syringyl) are based on different functional groups. H-phenolic contains 1, 2-Benzenediol, Hydroquinone and so on. 4-methoxy-3-methyl-phenol and 2-methoxy-phenol both belong to G-phenolic. S-phenolic consists of syringaldehyde, 2, 6-demethoxy-phenol and more. Temperature is considered to be one of the most important factors that affect pyrolysis products of biomass. In the study, $450,500,550^{\circ} \mathrm{C}$ was determined as the temperature to pyrolyze cellulose $(\mathrm{C}), \mathrm{xylan}(\mathrm{X})$ and $\operatorname{lignin}(\mathrm{L})$.

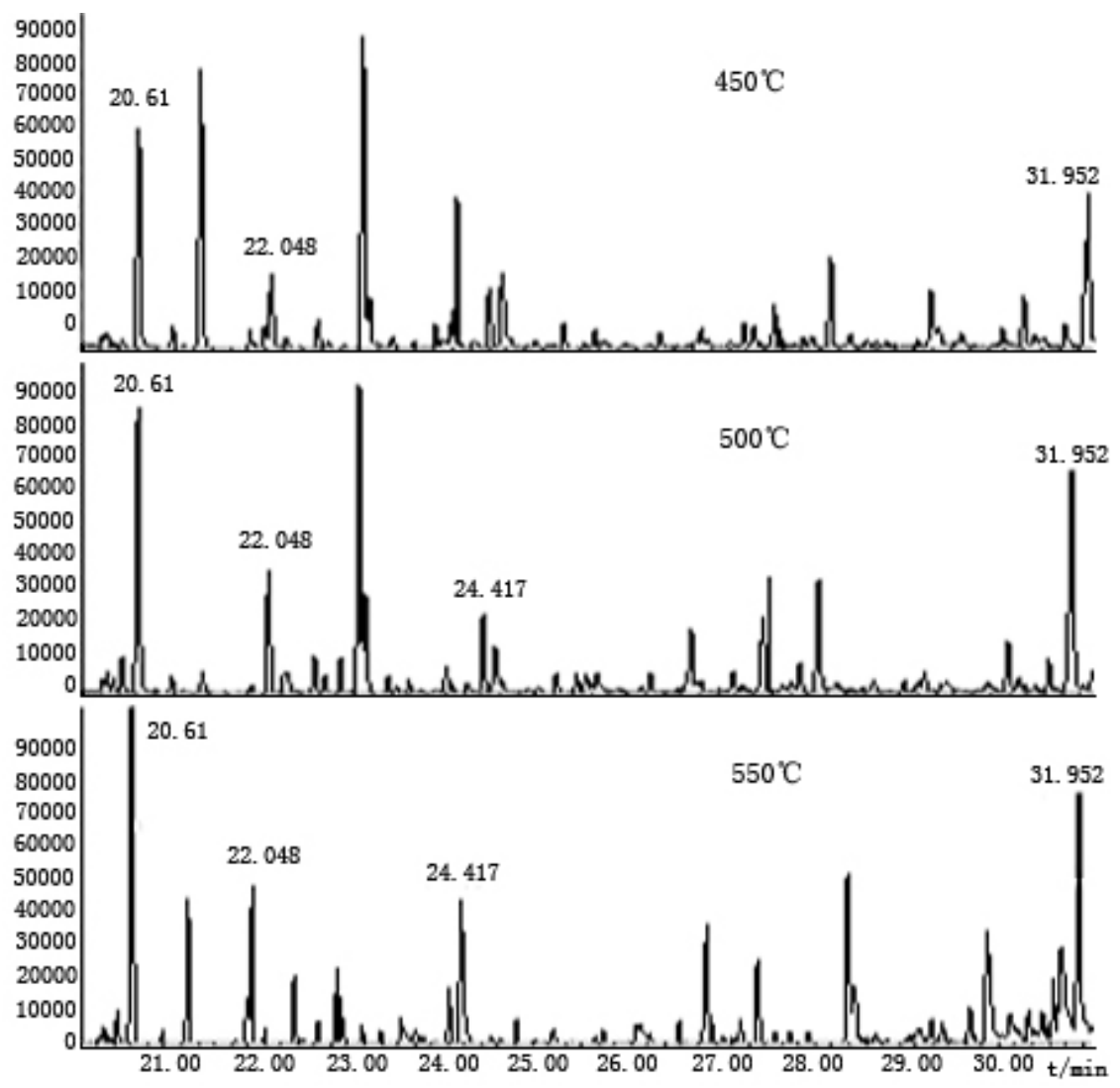

a. The content of phenols of cellulose pyrolysis oil 

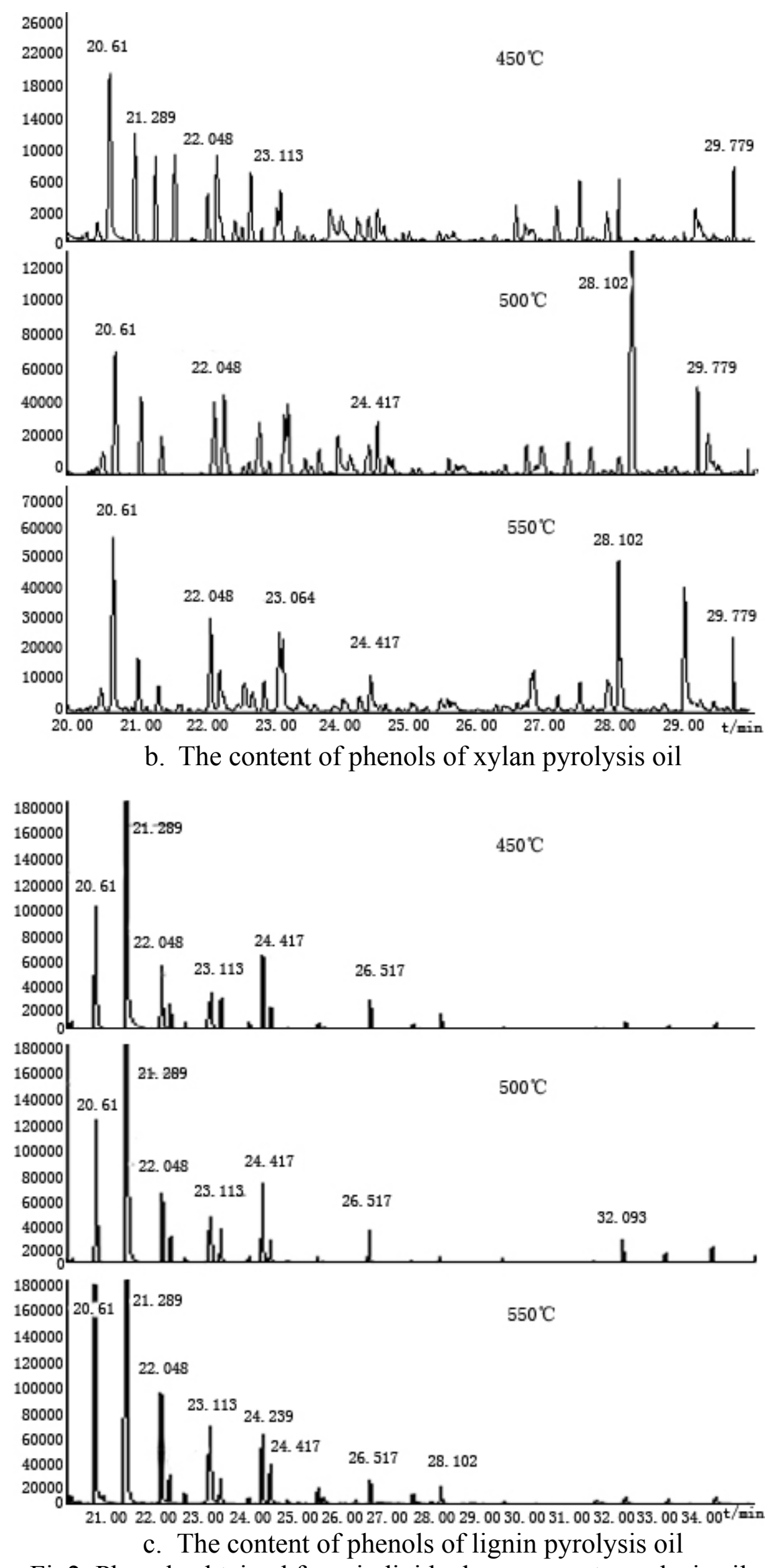

Fig2. Phenols obtained from individual component pyrolysis oil 
Table1. Chromatographic peak identification of phenols from three major components

\begin{tabular}{|c|c|c|c|c|c|c|c|c|c|c|c|}
\hline \multirow{4}{*}{ Time } & \multirow{4}{*}{ Phenols } & \multirow{4}{*}{ Formula } & \multicolumn{9}{|c|}{ Area $/ \%$} \\
\hline & & & \multicolumn{3}{|c|}{ Cellulose } & \multicolumn{3}{|c|}{ Xylan } & \multicolumn{3}{|c|}{ Lignin } \\
\hline & & & 450 & 500 & 550 & 450 & 500 & 550 & 450 & 500 & 550 \\
\hline & & & ${ }^{\circ} \mathrm{C}$ & ${ }^{\circ} \mathrm{C}$ & ${ }^{\circ} \mathrm{C}$ & ${ }^{\circ} \mathrm{C}$ & ${ }^{\circ} \mathrm{C}$ & ${ }^{\circ} \mathrm{C}$ & ${ }^{\circ} \mathrm{C}$ & ${ }^{\circ} \mathrm{C}$ & ${ }^{\circ} \mathrm{C}$ \\
\hline 20.61 & Phenol & $\mathrm{C}_{6} \mathrm{H}_{6} \mathrm{O}$ & 0.32 & 0.35 & 0.38 & 0.21 & 0.24 & 0.45 & 2.09 & 3.68 & 4.31 \\
\hline 21.289 & $\begin{array}{l}\text { Phenol, } \\
\text { 2-methoxy }\end{array}$ & $\mathrm{C}_{7} \mathrm{H}_{8} \mathrm{O}_{2}$ & - & - & - & 0.27 & - & & $\begin{array}{c}10.3 \\
3\end{array}$ & $\begin{array}{c}10.2 \\
6\end{array}$ & $\begin{array}{c}13.6 \\
4\end{array}$ \\
\hline 22.048 & $\begin{array}{l}\text { Phenol, } \\
\text { 2-methyl }\end{array}$ & $\mathrm{C}_{7} \mathrm{H}_{8} \mathrm{O}$ & 0.09 & 0.2 & 0.16 & 0.28 & 0.38 & 0.3 & 1.01 & 1.77 & 2.03 \\
\hline 22.556 & $\begin{array}{c}\text { Phenol, } \\
\text { 2,5-dimethyl }\end{array}$ & $\mathrm{C}_{8} \mathrm{H}_{10} \mathrm{O}$ & - & - & - & - & - & - & 0.12 & 0.12 & 0.18 \\
\hline 23.064 & $\begin{array}{l}\text { Phenol, } \\
\text { 4-methyl }\end{array}$ & $\mathrm{C}_{7} \mathrm{H}_{8} \mathrm{O}$ & - & - & - & - & - & - & 0.34 & 0.32 & 0.96 \\
\hline 23.113 & $\begin{array}{l}\text { Phenol, } \\
\text { 4-methyl }\end{array}$ & $\mathrm{C}_{7} \mathrm{H}_{8} \mathrm{O}$ & - & - & - & - & - & - & 0.65 & 0.46 & 1.44 \\
\hline 23.333 & $\begin{array}{l}\text { Phenol, } \\
\text { 2-methoxy- } \\
\text { 3-methyl }\end{array}$ & $\mathrm{C}_{8} \mathrm{H}_{10} \mathrm{O} 2$ & - & - & - & - & - & - & 0.38 & 0.46 & 0.45 \\
\hline 24.239 & $\begin{array}{l}\text { Phenol, } \\
\text { 2-methoxy- } \\
\text { 4-methyl }\end{array}$ & $\mathrm{C}_{8} \mathrm{H}_{10} \mathrm{O}_{2}$ & - & - & - & - & - & - & 1.23 & 0.87 & 1.25 \\
\hline 24.417 & $\begin{array}{c}\text { Phenol, } \\
\text { 2,5-dimethyl }\end{array}$ & $\mathrm{C}_{8} \mathrm{H}_{10} \mathrm{O}$ & - & 0.23 & 0.2 & - & - & 0.19 & 0.37 & 0.3 & 0.7 \\
\hline 25.439 & $\begin{array}{c}\text { Phenol, } \\
\text { 2,5-dimethyl }\end{array}$ & $\mathrm{C}_{8} \mathrm{H}_{10} \mathrm{O}$ & - & - & - & - & - & - & 0.13 & 0.1 & 0.29 \\
\hline 26.571 & $\begin{array}{l}\text { Phenol, } \\
\text { 4-ethyl-2- } \\
\text { methoxy }\end{array}$ & $\mathrm{C}_{9} \mathrm{H}_{12} \mathrm{O}_{2}$ & - & - & - & - & - & & 0.38 & 0.39 & 0.4 \\
\hline 28.102 & $\begin{array}{c}\text { Ethanone, } \\
\text { 1-(2-hydroxy-5 } \\
\text {-methylphenyl) }\end{array}$ & $\mathrm{C}_{9} \mathrm{H}_{10} \mathrm{O}_{2}$ & - & - & - & - & - & - & 0.28 & 0.12 & 0.33 \\
\hline 31.952 & Hydroquinone & $\mathrm{C}_{6} \mathrm{H}_{6} \mathrm{O}_{2}$ & 0.13 & 0.1 & 0.2 & 0.11 & 0.13 & 0.16 & - & - & - \\
\hline 32.093 & $\begin{array}{l}\text { Benzaldehyde, } \\
\text { 3-hydroxy-4-m } \\
\text { ethoxy }\end{array}$ & $\mathrm{C}_{8} \mathrm{H}_{8} \mathrm{O}_{3}$ & - & - & - & - & - & - & - & 0.33 & - \\
\hline 33.023 & $\begin{array}{c}\text { Phenol, } \\
\text { 5-methoxy-2,3, } \\
\text { 4-trimethyl }\end{array}$ & $\mathrm{C}_{10} \mathrm{H}_{14} \mathrm{O}_{2}$ & - & - & - & - & - & - & - & 0.17 & - \\
\hline 34.051 & $\begin{array}{c}\text { Ethanone, } \\
\text { 1-(4-hydroxy-3 } \\
\text {-methoxyphen } \\
\text { yl) }\end{array}$ & $\mathrm{C}_{9} \mathrm{H}_{10} \mathrm{O}_{3}$ & - & - & - & - & - & - & - & 0.25 & - \\
\hline 35.753 & $\begin{array}{c}\text { 3,4-Dihydroco } \\
\text { umarin-6-ol }\end{array}$ & $\mathrm{C}_{9} \mathrm{H}_{8} \mathrm{O}_{3}$ & - & - & - & - & 0.15 & 0.09 & - & - & - \\
\hline
\end{tabular}


According to Fig. 2, the GC/MS total ion chromatograms of the three major components (C, X and L) 450, 500, 550 were shown. The phenolic compounds in oil were listed in Table 1, in which these were grouped as phenols, H-phenols (derived from hydroxyphenyl), and G-phenols. It indicates that the side chains of benzene ring of S-phenols are prone to breakup at low condition $\left(\leq 450^{\circ} \mathrm{C}\right)$. For $\mathrm{C}$ and $\mathrm{X}$, the yields of phenolic compounds were relatively lower than that of $\mathrm{L}$ oil, which is due to the difference of structures of $\mathrm{C}, \mathrm{X}$ and $\mathrm{L}$.

As can be seen from Table 1, laevoglucose (LG) was the predominated component (the highest abundance at Fig. 2(a)) in cellulose oil. A small amount of them were found in the oil even no aromatic rings existing in the structure of $\mathrm{C}$. The total content of phenolic compounds had an upward trend consisted with the increase of temperature. At $500^{\circ} \mathrm{C}$, H-phenols content was the bottom while phenols content was the highest. This was probably because $500^{\circ} \mathrm{C}$ is the optimum temperature of the rearrangement of $\mathrm{H}$-phenols. The content of $\mathrm{H}$-phenols gradually went up from $0.1 \%$ to $0.2 \%$ and that of phenols fell from $0.78 \%$ to $0.74 \%$. It seems that hydroxylation of benzene exists at the pyrolysis conditions. On the other hand, no G-phenols and S-phenols were detected in the oil. Hence, it is consistent with the prior conclusion that the phenolic compounds are formed by the polymerization of fragments or radicals [16].

As for xylan oil, the yields of phenols, H-phenols and G-phenols were changed with increasing temperature. From table1, it is observed that the yield of phenols jumped from $0.44 \%$ to $1.03 \%$ and that of H-phenols slightly was increased from $0.11 \%$ to $0.16 \%$, while that of G-phenols greatly declined from $0.27 \%$ to a few, demonstrating that high temperature would promote the methoxyl of G-phenols to break off or to react with other radicals to produce water. It was worth noting that the total yield of phenolic compounds was increased but the amount of G-phenols only decreased. This is further confirmed that the polymerization of fragments or radicals and the depolymerization of methoxyl were simultaneous at $450 \sim 550^{\circ} \mathrm{C}$.

In the case of lignin oil, the yields of phenolic compounds from lignin were significantly higher than that of cellulose and xylan at pyrolysis conditions. 2-methoxy-phenol and phenol were regarded as typical products and possessed the larger proportion of the identified compounds, and accounted for more than $10 \%$ and $2 \%$, respectively. It is dues to the structure of lignin that are considered to be a three carbon chain which is attached to rings of six carbon atoms [17]. With the temperature raised from $450^{\circ} \mathrm{C}$ to $550^{\circ} \mathrm{C}$, the total yield of phenolic compounds sharply soared from $17.51 \%$ to $25.98 \%$, suggesting that the side chains are prone to depolymerize and aldehyde condense, recombination and cyclic reaction in succession with the increase of temperature. Meanwhile, there were no H-phenols in the oil. It also reveals that $\mathrm{C}-\mathrm{O}$ bond is more likely to depolymerize and rearrange to light oxygenic molecular. This is in agreement with the latest results by Xin et al. [18], who deduced that the primary reactions of lignin pyrolysis are depolymerization and dealkylation, and found that high temperature would promote guaiacol decomposition.

\subsection{The effect of interaction on phenolic compounds}

\subsubsection{Interaction between two components}

To study the exact interaction between two components (C-L, C-X and X-L), an ordinary equation was used to tell the difference of the experimental results from the calculational results $[8,19]$. In general, liquid product obtained the highest yield and the best quality when pyrolysis at $500^{\circ} \mathrm{C}$. Hence, $500^{\circ} \mathrm{C}$ was selected as the experiment temperature in the study. Based on comparing the mixed yields of phenols, H-phenols and G-phenols (no S-phenols existed in the oil) and calculating of that, the effect of interaction of two components on phenolic compounds was investigated in the study. The phenolic product yields were calculated from the following equation:

$$
\mathrm{Y}_{\mathrm{i}}=\mathrm{a} \mathrm{Y}_{\text {icellulose }}+\mathrm{b} \mathrm{Y}_{\text {ixylan }}+\mathrm{c} \mathrm{Y}_{\text {iligin }}
$$

Where Yi (peak area) was the content of different phenolic products in the study $(\mathrm{i}=1,2,3$ denoting phenols, H-phenols and G-phenols, respectively), a, b and c were the initial fractions of cellulose, hemicellulose and lignin (3/7, 3/7 and 1/7, respectively) in maize straw, respectively, and the phenolic products yields of cellulose, hemicellulose, and lignin were Yi,cellulose, Yi,xylan, and Yi,lignin, respectively. 
It is apparent from Fig3, the experimental and calculational results were observed, but the content of each phenolic product markedly differed from each other. The interaction that reduced the difference of the experimental and calculational results was presented in Fig. 4; the positive and negative were represent the promotion or inhabitation, respectively. The experimental yields of phenols and G-phenols were lower than the calculational results but the case of H-phenols was different in C-L pyrolysis oil, indicating the interaction between lignin and cellulose promotes the depolymerization and rearrangement of $\mathrm{C}-\mathrm{O}$ chains of guaiacyl to produce phenols and $\mathrm{H}$-phenols and inhibits the secondary decomposition $[20,21]$. The formation of phenolic from X-L was similar with that of C-L. As for phenolic production in C-X oil, it is found that the experimental results were little higher than these of the calculationed, implying that this interaction which slightly restrains the depolymerized fragmentation of xylan produce molecular fragments and promoting the aromatization to massively generate phenolic produce.

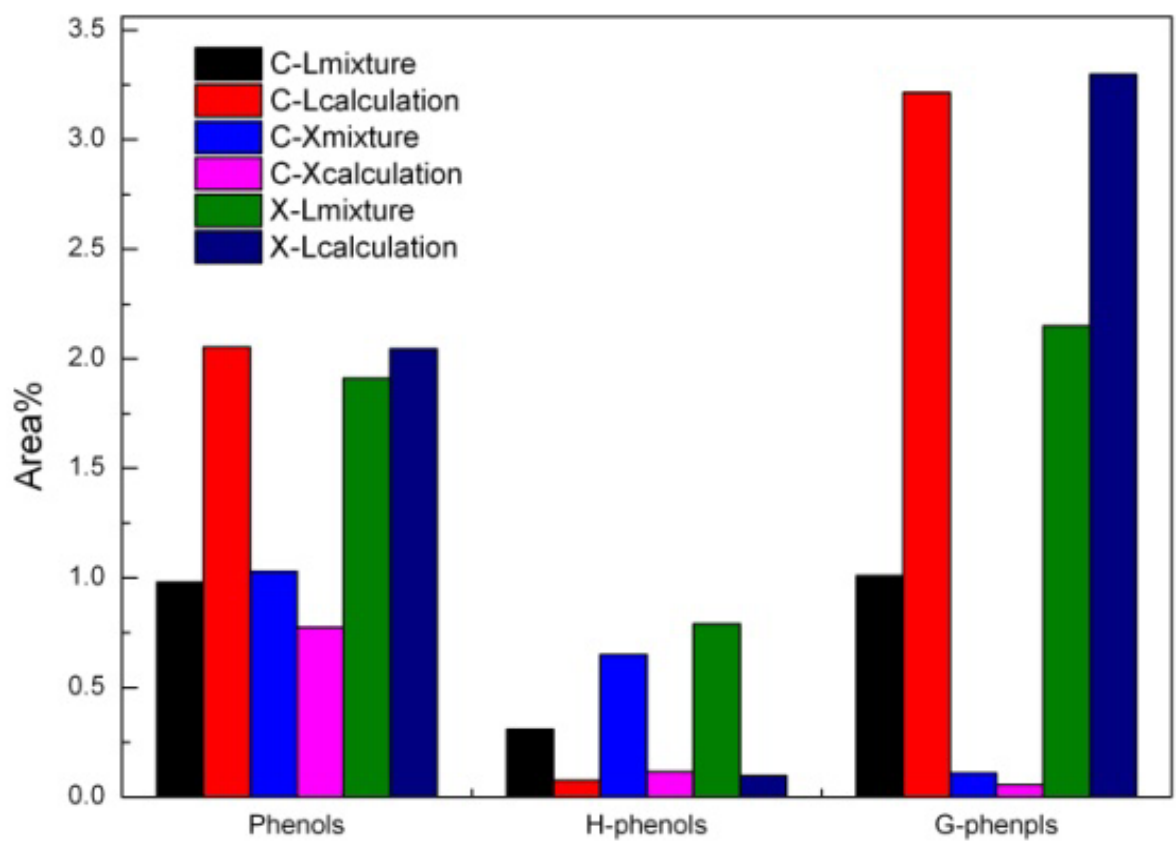

Fig. 3 Comparison between two-component experimental and calculational results at $500^{\circ} \mathrm{C}$

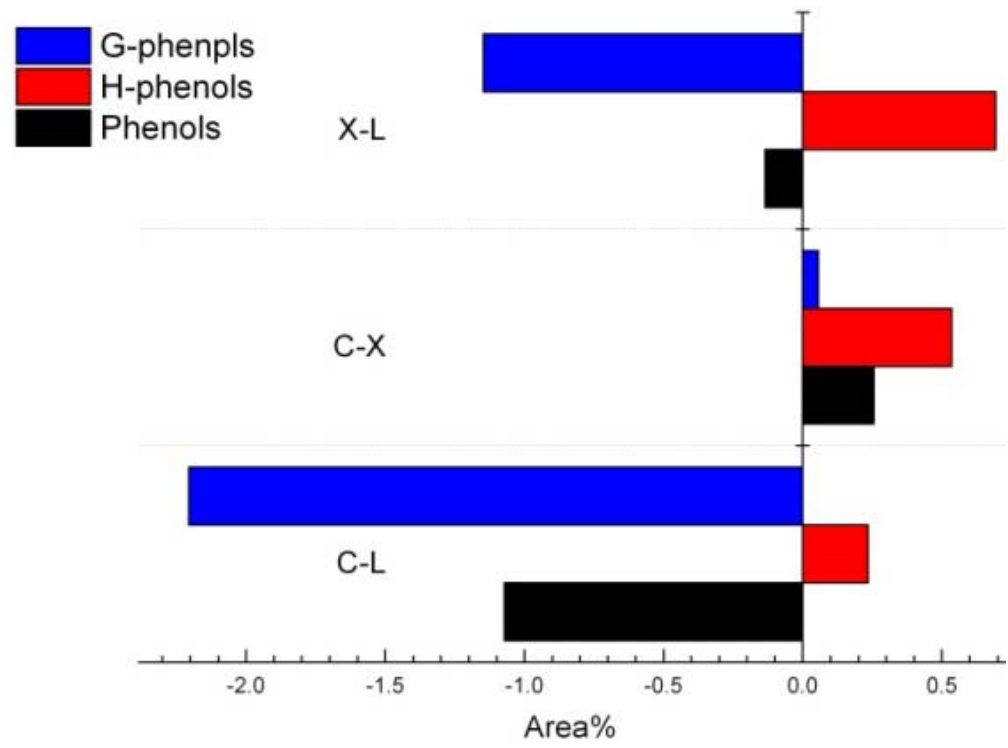

Fig. 4 Differences between two-component experimental and calculated results at $500^{\circ} \mathrm{C}$

\subsubsection{The simulation of maize straw pyrolysis with three components}

To study the interaction among three major components with superposition which had been reported by the previous investigation as above mentioned. Three components were conducted with mixing to 
3:3:1 based on the average proportion of maize straw [15]. In short, ash and organic extracts were considered as additional materials of hemicellulose or lignin to impact the production of biomass pyrolysis $[8,22]$. Due to the study which focused on the interaction between cellulose, hemicellulose and lignin was not compared with the produced obtaining from raw biomass. Furthermore the content of ash and organic extracts in biomass was few. Therefore the effect of these was not considered in this study. To simulate maize straw pyrolysis phenolic compounds also can be based on equation (1). Comparison of the contents of phenolic compounds experimental and calculational results and maize straw pyrolysis were presented in Fig. 5.

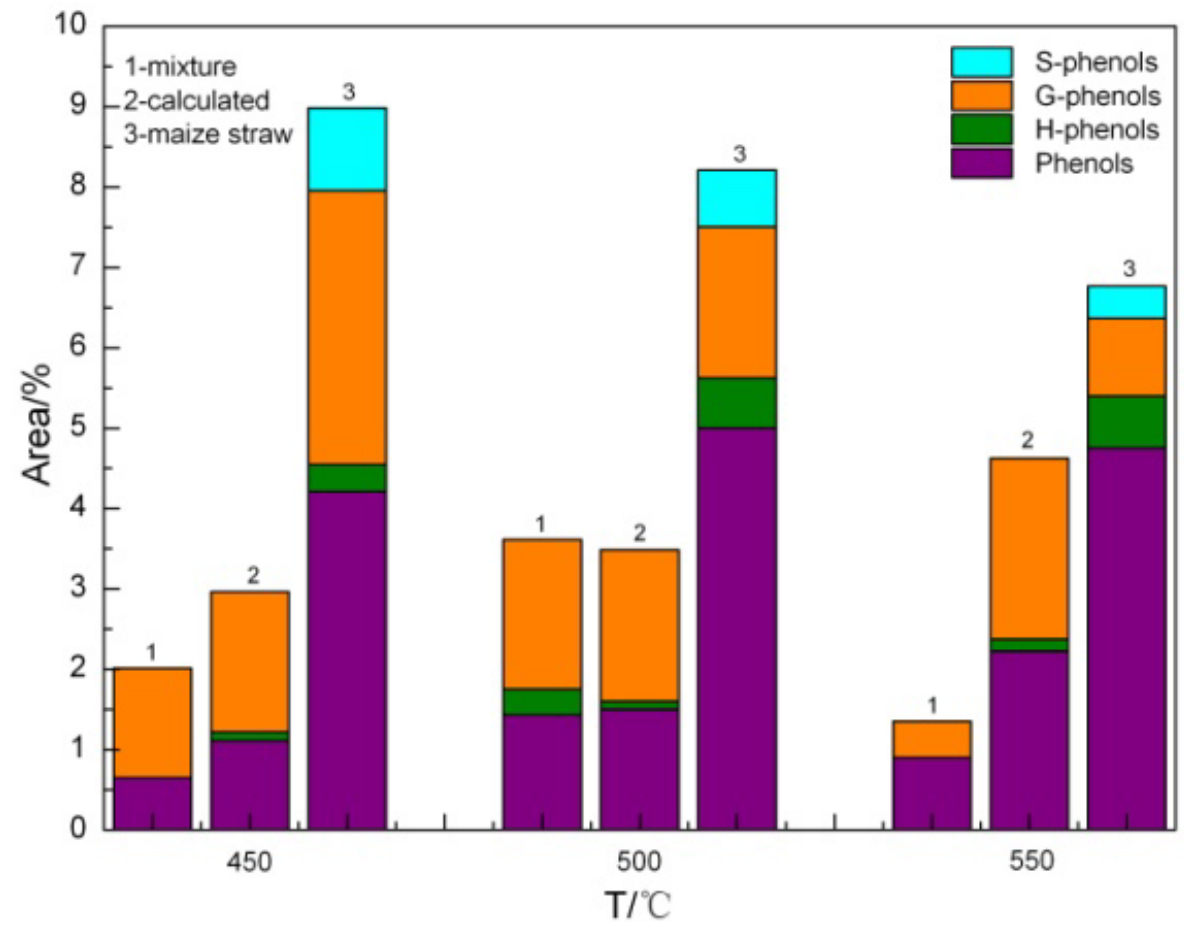

Fig. 5 Comparison among three-component experimental results, calculational results and maize straw results

As was shown in Fig. 5, there was clear difference between maize straw and modular material pyrolysis that S-phenols was generated in maize straw oil. By comparing the three components experimental results and maize straw pyrolysis, phenols was restrained clearly when the three components mixed and pyrolysis, besides macromolecule such as S-phenols and H-phenols were inhibited in the oil. The total yield of phenolic production in maize straw oil was higher obviously than the other. It is may be the reason that the basic structure is destroyed when the three components are extracted from raw biomass, especially lignin. Hence, it concludes that modular materials cannot simulate the raw biomass pyrolysis process. It is clear from Fig. 5, with regard to phenols, the experimental results $(0.65 \%, 1.43 \%$ and $0.9 \%$, respectively) were lower than those of the calculation $\left(1.11 \%, 1.50 \%\right.$ and $2.22 \%$, respectively) at 450,550 and $650^{\circ} \mathrm{C}$, respectively. $\mathrm{In}$ the case of $\mathrm{H}$-phenols, the experimental result $(0.32 \%)$ was higher than that of the calculation $(0.10 \%)$ at $500^{\circ} \mathrm{C}$ but $\mathrm{H}$-phenols was not detected in mixture pyrolysis oil at 450 and $550^{\circ} \mathrm{C}$. The experimental results of G-phenols $(1.36 \%, 1.86 \%$ and $0.45 \%$, respectively) were lower than those of the calculation $(2.22 \%$, $1.88 \%$ and $2.25 \%$, respectively). In addition, at each pyrolysis condition, the content of H-phenols lowered than the others. It may be the reasons that the hydroxyl attaching to aromatic is prone to secondary thermal polymerize to generate a large amount of phenols. As is shown by Fig.5, pyrolysis temperature is indeed a critical parameter that can affect not only the phenols yields but also the interaction among the three components on phenols. At $500^{\circ} \mathrm{C}$, the interaction promotes the hydroxylation of cellulose or xylan and the break of $\beta-\mathrm{O}-4$ and $\mathrm{C} \beta-\mathrm{C} 1$ ether bond for the connection of benzene propane in lignin polymer to generate a large amount of phenolic production, especially phenols, and the total content of three components pyrolysis oil reached the highest. Simultaneously, the interaction among the three components strongly impactes the G-phenols depolymerization, the G-phenols yields is remarkly inhibited at $550^{\circ} \mathrm{C}$ when three components were mixed to pyrolysis. 


\section{Conclusion}

Fast pyrolysis of cellulose, xylan and lignin conducted in tube furnace at different temperature and the effect of interactions among these on phenolic productions were investigated in this subject. The effects of temperature on phenols, H-phenols and G-phenols were remarkly in the experiment. S-phenols are not generated in the oils. The overall inclination of of xylan and lignin oils are consistent with temperature increased from 450 to $550^{\circ} \mathrm{C}$. In cellulose oil, H-phenols was prone to dehydroxylation near $500^{\circ} \mathrm{C}$. Lignin produced the highest phenolic compounds yields, with a highest yield of $25.98 \%$ at $550^{\circ} \mathrm{C}$.

The interactions of two-component effect the phenolic yields. Cellulose-lignin interactions promoted the phenols and G-phenols yields, and the generation of H-phenols was restrained. In cellulose-xylan oil, the content of phenolic compounds was almost equal to the calculated results by individual pyrolysis oil. The phenolic yields in xylan-lignin oil changed just as sharply as cellulose-lignin.

At each pyrolysis condition, the interaction on H-phenols was stronger to induce the content of H-phenols lowered than others'. Phenolic content of the three components pyrolysis oil reached the highest at $500^{\circ} \mathrm{C}$, and G-phenols yields was remarkly inhibited at $550^{\circ} \mathrm{C}$. The total content of phenolic production in maize straw oil was higher than modular material oil, and the content of phenols and S-phenols were restrained clearly.

\section{Acknowledgements}

This work was financially supported by The National Natural Science Foundation of China (51276103, 51406109), Key Projects of NSFC (51536009) and Distinguished Expert of Taishan Scholars Shandong Province.

\section{References}

[1] S.R. Wang, K.G. Wang, Q. Liu, Y.L. Gu, Z.Y. Luo, K.F. Cen, F. Torsten. Biotechnol. Adv, 2009, 27(5):562-567.

[2] Qiang Lu, Xifeng Zhu, Quanxin Li, Qingxiang Guo, Qingshi Zhu. Progress In Chemistry, 2007, 19(7/8): 1064-1071.

[3] Xuejing Gao, Jianmin Chang, Shouqiang Xu, Xueyong Ren. China Adhesives, 2012, 21(5):1034-1037. In Chinese.

[4] R. Alén, E. Kuoppala, P. Oesch. J. Anal. Appl. Pyrolysis, 1996, 36(2):137-148.

[5] E. Ranzi, A. Cuoci, T. Faravelli, A. Frassoldati, G. Migliavacca, S. Pierucci, S. Som-mariva. Energy Fuels, 2008, 22(6): 4292-4300.

[6] Chao Liu, Jinbao Huang, Xiaolu Huang, Haojie Li, Zhi Zhang. Computational and Theoretical Chemistry, 2011, 964(1-3): 207-212.

[7] Yinxuan Fu, Haibin Zhu, Yanzhi Sun, Yongmei Chen, Pinyu Wan. Advanced Materials Research. 2013, 663(295-298):392-396.

[8] Kun Zhao, Jun Xiao, Laihong Shen, Tingting Qu. Acta Energiae Solaris Sinica, 2011, 32(5): 710-717. In Chinese.

[9] E. Biagini, A. Federica Barontini, L. Tognotti. Ind. \&Eng. Chem. Res., 2006, 45(13): 4486-4493.

[10]Na Huang. Study on Pyrolysis Characteristics and Kinetics of Three Components of Biomass. Beijing University of Chemical Technology, 2007. In Chinese.

[11]T. Hosoya, H. Kawamoto, S. Saka. Journal of Analytical \& Applied Pyrolysis, 2007, 80(1): $118-125$ 
[12]C Couhert, JM Commandré, S Salvador. Biomass and Bioenergy, 2009, 33(2): 316-326.

[13] Yun Wang. Experimental Study of Biomass Pyrolysis Characteristics Based on Components Analysis. Shanghai Jiao Tong University, 2012. In Chinese.

[14]MR Hajaligol, JB Howard, JP Longwell, WA Peters. Industrial \& Engineering Chemistry Process Design and Development. 1982, 21(3): 457-465.

[15]Liying Liu, Hongzhang Chen. Spectroscopy and Spectral Analysis, 2007, 27(2): 275-278. In Chinese.

[16] Scheer AM, Mukarakate C, Robichaud DJ, Ellison GB, Nimlos MR. J Phys Chem A, 2010, 114(34): 9043-9056.

[17]Peter M. Bioresource Technology, 2002, 83(1):37-46.

[18] Shanzhi Xin, Haiping Yang, Yingquan Chen, Xianhua Wang, Hanping Chen. Fuel, 2013, 113: 266-273.

[19]T Qu, W Guo, L Shen, J Xiao, K Zhao. Industrial \& Engineering Chemistry Research, 2011, 50(18):10424-10433

[20]DK Shen, S Gu, AV Bridgwater. Carbohydrate Polymers, 2010, 82(1): 39-45.

[21]WH Chen, PC Kuo. Energy, 2011, 36(11): 6451-6460.

[22] Yongmei Pang. Study on Pyrolysis Experiment and Kinetics of Biomass. North China Electric Power University, 2007. In Chinese. 